\title{
Racial Differences in Generalized Anxiety Disorder During the COVID-19 Pandemic among Brazilian University Students: a National Survey
}

\author{
André Eduardo da Silva Júnior ${ }^{1}$ (D) - Mateus de Lima Macena ${ }^{2}$ (D) - Ana Debora Santos de Oliveira ${ }^{2}$ (I) \\ Dafiny Rodrigues Silva Praxedes ${ }^{2}$ (D) - Isabele Rejane de Oliveira Maranhão Pureza ${ }^{1}$ (D) Nassib Bezerra Bueno ${ }^{1,2}$ (D)
}

Received: 24 April 2021 / Revised: 6 July 2021 / Accepted: 7 July 2021 / Published online: 21 July 2021

(C) W. Montague Cobb-NMA Health Institute 2021, corrected publication 2021

\begin{abstract}
There is evidence that during the COVID-19 pandemic, there was an increase in anxiety and depression rates among college students. However, little is known about how generalized anxiety disorder (GAD) developed among individuals of different race/ skin color. This study aimed to determine whether there are racial differences in GAD in Brazilian university students during the COVID-19 pandemic. This is a nationwide cross-sectional study, carried out through the application of online questionnaires to university students from 94 Brazilian universities. Self-reported data on age, sex, economic class, race/skin color, anthropometric data, and adherence to social distancing measures were collected. To determine the GAD, the Generalized Anxiety Disorder 7item scale was applied. A total of 5879 participants were included, with a mean age of $24.1 \pm 6.4$ years, and the majority were female $(n=4324,73.5 \%)$, most self-declared to be whites $(n=2945,50.1 \%)$, followed by browns $(n=2185,37.2 \%)$ and blacks $(n=749,12.7 \%)$. The prevalence of GAD among black Brazilian university students $(47.3 \%$ [95\% CI 43.7, 50.8]) was significantly higher than that of browns (38.6\% [95\% CI 36.6, 40.7]) and whites (44.1\% [95\% CI 42.3, 45.9]), even after multivariable adjustment by other sociodemographic factors. The findings of the present study suggest a possible racial difference in GAD among Brazilian university students, in which those who declared their race/skin color as black showed a greater risk for GAD than those who declared themselves as white or brown.
\end{abstract}

Keywords Race $\cdot$ Ethnicity $\cdot$ GAD-7 $\cdot$ Mental health $\cdot$ SARS-CoV-2

\section{Introduction}

The World Health Organization (WHO) declared, on March 11, 2020, the pandemic of the disease caused by the infection with the new coronavirus (COVID-19) [1]. Due to its rapid spread and important impact on population morbidity and mortality, measures to contain the spread of the SARSCoV-2 virus have been implemented worldwide. Among these measures, quarantine, social distancing, and social isolation resulted in the closure of commerce, public outdoor spaces (i.e., squares, parks, and beaches), schools, and universities [2, 3].

Nassib Bezerra Bueno

nassib.bueno@fanut.ufal.br

1 Programa de Pós-Graduação em Nutrição, Escola Paulista de Medicina, Universidade Federal de São Paulo, São Paulo, SP, Brazil

2 Faculdade de Nutrição, Universidade Federal de Alagoas, Maceió, AL 57072-970, Brazil
The impacts of the COVID-19 pandemic and measures of social distancing on the health of the population in different stages of the life cycle have already been reported, in both adolescents and adults [4-7]. University students are known as a vulnerable public for mental health problems [8], and the effects of the pandemic were also observed in this population, among which the high rates of anxiety and depression are associated with concerns regarding their health, academic performance, and decreasing family income $[4,6,9,10]$.

In Brazil, few studies have evaluated the relationship between race/skin color and the mental health of the population. Although there is no formal policy of racial segregation in Brazil, the country has important inequalities related to the race/skin color of individuals, whether in educational, financial, or social opportunities [11-15]. The paths that link race/ skin color and mental health involve stress associated with the economic class, social roles, social structure, racism, and discrimination [16]. Therefore, given the influence of race/skin color and the consequences of the COVID-19 pandemic on the mental health of university students, this study aimed to 
determine whether there are racial differences in generalized anxiety disorder (GAD) in Brazilian university students during the COVID-19 pandemic.

\section{Methods}

\section{Ethical Aspects}

The research protocol was approved by the Research Ethics Committee of the Universidade Federal de Alagoas (opinion number: 4,410,403). All participants were presented with the free and informed consent form (FICF). After accessing the survey link, the participants were introduced to the FICF that was on the first page of the virtual questionnaire, and it was necessary to accept it to access the questionnaire and start data collection.

\section{Study Design}

This is a cross-sectional study.

\section{Location and Sample}

This study is a secondary analysis of the project entitled "Prevalence of food addiction in university students during the COVID-19 pandemic," conducted among Brazilian university students, from 94 public and private universities, from all 27 federative units (26 states and the Federal District [federal capital]) of Brazil. Administratively, the country is divided into 27 federative units that make up its five macro-regions: North, Northeast, Midwest, Southeast, and South [17]. Data collection took place by completing an online questionnaire between October 27 and December 11 (between the 44th and the 50th epidemiological week) of 2020. During the year 2020, Brazil was between two peaks of cases and deaths, in which in the 30th epidemiological week, the country presented 319,653 and 7677 absolute numbers of cases and deaths, respectively, and during the 51st epidemiological week of 2020 with absolute numbers of 333,028 new cases and 5233 deaths [18].

Undergraduate students from any area of knowledge, of both sexes, aged between 18 and 59 years were included. Subjects submitted to bariatric surgery, pregnant women, and lactating women were not included. Participants who sent incomplete questionnaires, who reported unlikely values for anthropometric variables (weight or height), or those who chose not to report race/skin color were excluded from the analysis. The recruitment of participants took place through invitations sent by e-mails and publications on websites and institutional social networks.

\section{Demographic and Clinical Variables}

Data on age (in years), date of birth, sex, educational institution that was linked, federative unit, race/skin color, and whether they had a medical diagnosis of depression were collected. We adopted the method proposed by the Instituto Brasileiro de Geografia e Estatística (IBGE) to collect race/ skin color data, in which the individual should self-report his identification as white (Caucasian), black (Afro-descendant), brown, yellow (Asian), and indigenous [17]. In Brazil, the term "browns" is used to refer to people with mixed race/ skin colors.

\section{Economic Class}

The Critério de Classificação Econômica Brasil was used to determine the economic class of the participants. This instrument consists of questions about property ownership, the presence of monthly domestic employees, and the number of bathrooms in the home. Also considered is the level of education of the head of the family and access to public services such as piped water and paved street. A value is assigned to each answer, and a sum of the scores is made for each individual, which can vary from 0 to 100 points, the highest scores correspond to a higher estimated monthly family income. Individuals were classified into six economic classes: "A" (45-100 points), "B1" (38-44 points), "B2" (29-37 points), "C1" (23-28 points), "C2" (17-22 points), "D-E" (0-16 points) [19].

\section{Adherence to Social Distancing and Medical Diagnosis of COVID-19}

Adherence to the social distancing measures was also selfreported and collected through the following question "Did you follow the social distancing measures?" The participants could answer "I followed the social distancing most of the time, performing only trips to supermarkets and pharmacies," "I followed the social distancing, but I had to leave to work," or "I didn't follow the social distancing".

The medical diagnosis of COVID-19 was self-reported and collected through a direct question "Did you have a medical diagnosis of COVID-19?" with dichotomous response (yes or no). Medical tests or certificates were not collected to confirm the information provided.

\section{Anthropometry}

Height (in meters) and body weight (in kilograms) data were self-reported. The body mass index (BMI) was calculated and classified as underweight $\left(\mathrm{BMI}<18.5 \mathrm{~kg} / \mathrm{m}^{2}\right)$, normal weight (BMI between 18.5 and $24.9 \mathrm{~kg} / \mathrm{m}^{2}$ ), overweight (BMI between 25.0 and $29.9 \mathrm{~kg} / \mathrm{m}^{2}$ ), and obese (BMI $\geq 30 \mathrm{~kg} / \mathrm{m}^{2}$ ), 
according to the cutoff points proposed by the World Health Organization [20].

\section{Generalized Anxiety Disorder}

The Generalized Anxiety Disorder 7-items scale (GAD-7) was developed to identify GAD [21]. GAD-7 also demonstrated good sensitivity and specificity as a tool for screening for panic, social anxiety, and post-traumatic stress disorder [22]. This tool was translated into Portuguese by Pfizer (Copyright (C) 2005 Pfizer Inc., New York, NY) and has a record of evidence of validity in Brazil [23]. It consists of seven items, arranged on a Likert scale with four points ranging from 0 to 3 , where 0 represents "not at all" and 3 "nearly every day"; the score is added and can vary from 0 to 21 points. It was considered a probable case of GAD, scores equal to or greater than 10 [21]. Cronbach's $\alpha$ for this sample was 0.90 .

\section{Statistical Analysis}

In the descriptive analysis, data are presented as mean and standard deviation for continuous variables and frequencies for categorical variables. Poisson regression with robust adjustment of variances was used to identify the factors associated with GAD (dependent variable), in univariable analyses and in multivariable models that included age (in years), sex, race/skin color, economic class, depression diagnosis, COVID-19 diagnosis, BMI classification, and adherence to social distancing measures during the COVID-19 pandemic, as independent variables. Prevalence ratios (PR) and their respective $95 \%$ confidence intervals $(95 \% \mathrm{CI})$ are presented. We adopted $\alpha$ equal to $5 \%$ for all analyses. All statistical analyses were conducted using the software R v 3.6.1 (R Foundation for Statistical Computing, Vienna, Austria).

\section{Results}

In all, 6532 questionnaires were sent to the online platform; however, after cleaning the database, 548 were excluded; Fig. 1 shows the flowchart of the participants. In addition, we excluded from this analysis individuals who declared themselves yellow $(n=72)$ and indigenous $(n=33)$, due to the small sample size, totalling 653 excluded individuals. Thus, 5879 participants were included in this analysis.

The mean age of the sample was $24.1 \pm 6.4$ years; the majority were female $(n=4324,73.5 \%)$ and lived in the Northeast $(n=2589,44.0 \%)$. The vast majority were from economic class B2 $(n=1773,30.2 \%)$ and $\mathrm{C} 1(n=1210$, $20.6 \%)$ and were of adequate weight $(3263,55.5 \%)$ according to the BMI, and $849(14.4 \%)$ reported having the medical diagnosis of depression. Regarding race/skin color, most self-declared to be whites $(n=2945,50.1 \%)$, followed by browns $(n=2185,37.2 \%)$ and blacks $(n=749,12.7 \%)$. Table 1 describes the characteristics of the included sample. The prevalence of GAD was $44.1 \%$ (95\% CI 42.3, 45.9) among whites, $47.3 \%$ (95\% CI 43.7, 50.8) among blacks, and $38.6 \%(95 \%$ CI 36.6, 40.7) among browns. In the present sample, the average score on the GAD- 7 was $9.7 \pm 5.5$ points.

Univariable and multivariable analyses between demographic, social, economic, clinical, and GAD indicative variables are shown in Table 2. After adjustment, the association between GAD and age (in years) (PR 0.98; 95\% CI 0.97, 0.98; $p<0.01$ ) and the female gender (PR 1.32; 95\% CI 1.22, 1.43; $p<0.01)$ remained significant. An association was observed between GAD and race/skin color in general (omnibus test $p<$ $0.01)$. Specifically, the association with black race/skin color (PR 1.10; 95\% CI 1.01, 1.20; $p=0.02$ ) and brown (PR 0.92; 95\% CI 0.86, 0.98; $p=0.01$ ), using the race/skin color "white" as the reference category, was significant. An association was also observed with the BMI classes (omnibus test $p<0.01$ ), with overweight (PR 1.15; 95\% CI 1.07, 1.24; $p<0.01$ ) and obesity (PR 1.29; 95\% CI 1.19, 1.40; $p<0.01$ ), while using the normal weight as the reference. The medical diagnosis of depression was associated with GAD (PR 1.78; 95\% CI 1.69, $1.89 ; p<0.01)$. Regarding adherence to social distancing, an association with GAD was observed (omnibus test $p<0.01$ ), partial adherence to measures of social distancing (i.e., leaving home to work) (PR 1.08; 95\% CI 1.01, 1.15; $p=0.01$ ), with total adherence to social distancing (i.e., leaving home only for going to the supermarket and pharmacy) being the reference category. No association was observed between GAD, COVID-19 diagnosis, and any particular economic class.

\section{Discussion}

In this study, we investigated the differences in race/skin color in the GAD in a representative sample of Brazilian university students during the COVID-19 pandemic. Our results indicate that GAD was associated with black/brown skin races/colors, in multivariable analyses. These findings indicate that the prevalence of GAD among black Brazilian university students (47.3\% [95\% CI 43.7; 50.8]) was higher than that of browns $(38.6 \%$ [95\% CI 36.6, 40.7]) and whites $(44.1 \%$ [95\% CI] $42.3,45.9]$ ), remaining significant in the multivariable analysis, adjusting for several sociodemographic factors. Furthermore, we did not observe an association between GAD and economic class.

High rates of anxiety, depression, psychological distress, and stress have been reported in the general population during the COVID-19 pandemic [24]. University students are, in particular, a vulnerable group for the development of mental health problems, and, therefore, the impacts of the COVID19 pandemic on the mental health of this group have also been investigated [8]. In this public, higher prevalences of anxiety 
Fig. 1 Flowchart of study participants

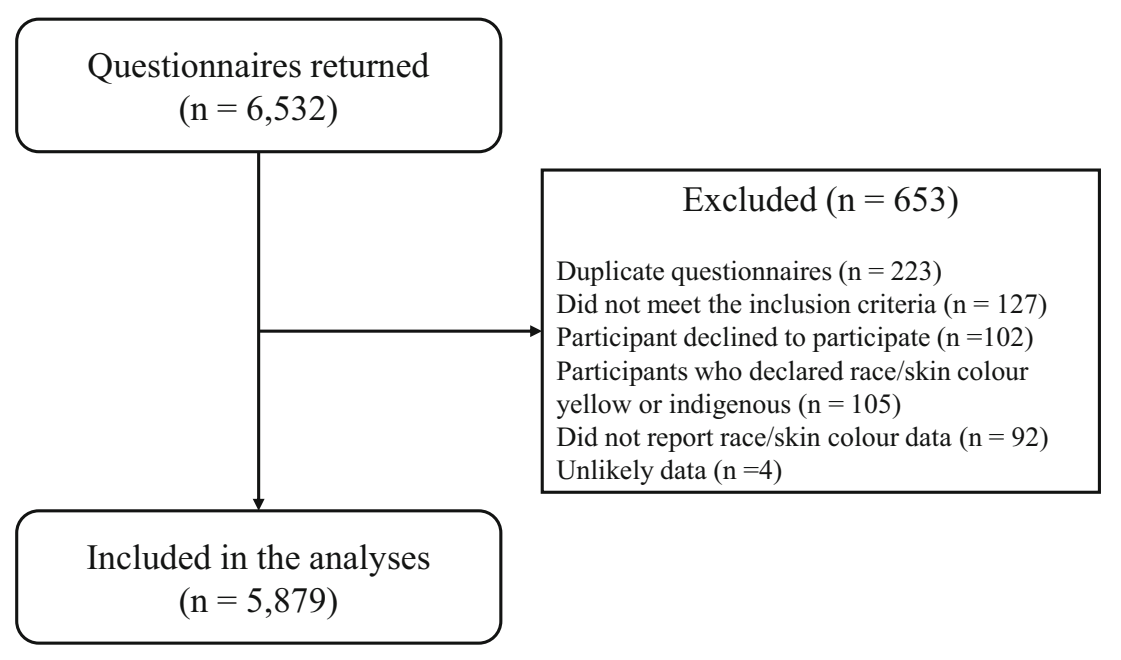

and depression were observed and were related to the fear of being contaminated or that their family members were contaminated by SARS-CoV-2, economic and academic issues $[4,6,9,10]$.

Racial and ethnic differences were investigated in specific mental health conditions, such as common mental disorder, depression, and, to a lesser extent, anxiety disorders. Concerning anxiety, findings contrary to what was observed in our research were found in a study conducted between March 29 and 31, 2020, in the USA. This study evaluated 1005 participants and observed that respondents who identified themselves as black were less likely to meet the anxiety criteria used in GAD-7 than the participants who identified themselves as white [25]. The pre-pandemic findings are contradictory, where Merikangas et al. [26] observed higher rates of anxiety disorders among black non-Hispanic adolescents when compared to non-Hispanic whites. Asnaani et al. [27] noted that African Americans were less likely to have GAD than white Americans. However, Williams et al. [28] observed a greater chronicity of major depressive disorder and a greater degree of functional impairment in African Americans in the USA.

In our study, individuals who self-report to be brown had the lowest prevalence of GAD among the groups evaluated. We are unaware of studies that have evaluated GAD in this group; however, other mental health conditions have already been investigated. Bastos et al. [29] conducted a study with 424 Brazilian university students and found a lower prevalence of common mental disorders in self-declared brown individuals $(32.8 \%)$ than self-declared white individuals $(37.0 \%)$. Another study conducted in Brazil, with women aged between 15 and 45 years and who were between 35 and 180 days after delivery, found that brown women also had a lower prevalence of postnatal depression than white women [30]. It is worth mentioning that in Brazil, the selfattribution of race/skin color is mainly due to physical characteristics such as skin color, the shape of the nose and lips, and the type of hair, with the physical traits of blacks and browns socially devalued [31]. In addition, there is a strong relationship between race/skin color and socioeconomic status in the country, to the point of black and brown individuals, who have ascended socially, identify themselves and be socially recognized as white $[31,32]$.

Moreover, in Brazil, self-declaration of race/skin color brown is complex and permeates biological, economic, and, mainly, social issues. A paradox is observed concerning Brazilians who declare themselves black and brown, while the analysis of social and economic indicators, income inequality, educational opportunities, and mobility patterns point to extreme proximity between these two groups, the browns systematically identify a lower perception of racial discrimination when compared to blacks. In addition, browns belonging to the higher economic classes do not report feeling discrimination, while blacks from the same classes report more frequently [33]. Some classical theories, such as "whitening" and "the mulatto escape valve," could contribute to the understanding of the relationships that involve whites and non-whites in the Brazilian socioeconomic scenario. Thus, we can hypothesize that brown individuals, for having a low perception of racial discrimination, could present lower rates of GAD than black individuals.

The growing body of evidence points to the association of racial discrimination with worse mental health status [34, 35]. In the African American community, racial discrimination was indicated as an important risk factor for physical and mental health, including depression [36]. On the other hand, a strong sense of ethnic identity among African Americans has proved to be a protective factor against mental health problems [37]. In Brazil, a study showed that black Brazilians have a 50\% greater chance than whites of having an experience of discrimination, even after adjusting for salary, education, social status, and health problems [38]. In this perspective, the findings by Bastos et al. [29] point out that the discrimination attributed to race/skin color was independently associated 
Table 1 Characteristics of the study participants

\begin{tabular}{|c|c|c|}
\hline \multirow[t]{2}{*}{ Variables } & \multicolumn{2}{|c|}{$\begin{array}{l}\text { All } \\
(n=5879)\end{array}$} \\
\hline & $n$ & $\%$ \\
\hline \multicolumn{3}{|l|}{ Sex } \\
\hline Female & 4324 & 73.5 \\
\hline Male & 1555 & 26.5 \\
\hline \multicolumn{3}{|l|}{ Region } \\
\hline North & 369 & 6.3 \\
\hline Northeast & 2589 & 44.0 \\
\hline Midwest & 365 & 6.2 \\
\hline Southeast & 1701 & 28.9 \\
\hline South & 855 & 14.5 \\
\hline \multicolumn{3}{|l|}{ Race/color } \\
\hline White (Caucasian) & 2945 & 50.1 \\
\hline Black (Afro-descendant) & 749 & 12.7 \\
\hline Brown & 2185 & 37.2 \\
\hline \multicolumn{3}{|l|}{ Economic class } \\
\hline A & 814 & 13.8 \\
\hline B1 & 935 & 15.9 \\
\hline B2 & 1773 & 30.2 \\
\hline $\mathrm{C} 1$ & 1210 & 20.6 \\
\hline $\mathrm{C} 2$ & 824 & 14.0 \\
\hline D-E & 323 & 5.5 \\
\hline \multicolumn{3}{|l|}{ Body mass index } \\
\hline Underweight & 447 & 7.6 \\
\hline Normal weight & 3263 & 55.5 \\
\hline Overweight & 1339 & 22.8 \\
\hline Obesity & 830 & 14.1 \\
\hline \multicolumn{3}{|l|}{ Depression diagnosis } \\
\hline Yes & 849 & 14.4 \\
\hline No & 5030 & 85.6 \\
\hline \multicolumn{3}{|l|}{ Diagnosis of COVID-19 } \\
\hline Yes & 413 & 7.0 \\
\hline No & 5466 & 93.0 \\
\hline \multicolumn{3}{|l|}{ Social distancing } \\
\hline $\begin{array}{l}\text { Adhered to social distancing for most of the time, performing only visits to supermarkets and } \\
\text { pharmacies }\end{array}$ & 4337 & 73.8 \\
\hline Adhered to social distancing, but had to leave to work & 1362 & 23.2 \\
\hline Did not adhere to social distancing & 180 & 3.1 \\
\hline
\end{tabular}

with a fourfold increase in the chance of common mental disorders in Brazilian university students, revealing the important contribution of racial discrimination in the mental health of the population.

Smolen and Araújo [39] conducted a systematic review in order to synthesize the findings about race/skin color and mental disorders (depression, anxiety, and common mental disorder) in Brazil. Among the findings of this review, the authors report a higher prevalence of mental disorders in the black population than in the white population in studies conducted before the COVID-19 pandemic. They also highlight the scarcity of studies that evaluated the relationship between anxiety and race/skin color [39]. Particularly in Brazil, there are important disparities in educational, financial, and social opportunities linked to racial disparities [11, 12]. Chor and Lima [40] believe that the scarcity of epidemiological research relating to race/skin color occurs due to three possible hypotheses: (I) the difficulties of ethnic-racial classification; (II) the acceptance of the "myth of racial democracy," and (III) the opposition between economic class and race/skin 
Table 2 Prevalence ratios from univariable and multivariable analysis for the diagnosis of general anxiety disorder in Brazilian university students according to demographic, clinical, anthropometrics, and social and economic variables

\begin{tabular}{|c|c|c|c|c|c|c|}
\hline \multirow[t]{2}{*}{ Variables } & \multicolumn{3}{|c|}{ Univariable analysis } & \multicolumn{3}{|c|}{ Multivariable analysis ${ }^{a}$} \\
\hline & PR & IC $95 \%$ & $p$ & PR & IC $95 \%$ & $p$ \\
\hline Age (in years) & 0.99 & $0.98,0.99$ & $<0.01$ & 0.98 & $0.97,0.98$ & $<0.01$ \\
\hline Sex & & - & & & - & \\
\hline Male & 1.00 & - & & 1.00 & - & \\
\hline Female & 1.41 & $1.30,1.57$ & $<0.01$ & 1.32 & $1.22,1.43$ & $<0.01$ \\
\hline Race/color & & - & $<0.01$ & & - & $<0.01$ \\
\hline White & 1.00 & - & & 1.00 & - & \\
\hline Black (Afro-descendant) & 1.07 & $0.98,1.16$ & 0.11 & 1.10 & $1.01,1.20$ & 0.02 \\
\hline Brown & 0.87 & $0.81,0.93$ & $<0.01$ & 0.92 & $0.86,0.98$ & 0.01 \\
\hline Economic class & & - & 0.14 & & - & 0.02 \\
\hline A & 1.00 & - & & 1.00 & - & \\
\hline B1 & 0.90 & $0.80,1.01$ & 0.08 & 0.90 & $0.80,1.00$ & 0.06 \\
\hline B2 & 1.00 & $0.91,1.10$ & 0.91 & 1.02 & $093,1.12$ & 0.65 \\
\hline $\mathrm{C} 1$ & 1.08 & $0.98,1.20$ & 0.10 & 1.07 & $0.97,1.18$ & 0.17 \\
\hline $\mathrm{C} 2$ & 0.95 & $0.85,1.07$ & 0.44 & 0.98 & $0.88,1.10$ & 0.81 \\
\hline $\mathrm{D}-\mathrm{E}$ & 0.96 & $0.82 ; 1.12$ & 0.65 & 1.01 & $0.87 ; 1.17$ & 0.88 \\
\hline Body mass index & & - & $<0.01$ & & - & $<0.01$ \\
\hline Normal weight & 1.00 & - & & 1.00 & - & \\
\hline Underweight & 0.96 & $0.84,1.08$ & 0.53 & 0.93 & $0.83,1.05$ & 0.27 \\
\hline Overweight & 1.13 & $1.05,1.21$ & $<0.01$ & 1.15 & $1.07,1.24$ & $<0.01$ \\
\hline Obesity & 1.32 & $1.22,1.43$ & $<0.01$ & 1.29 & $1.19,1.40$ & $<0.01$ \\
\hline Depression diagnosis & & - & & & - & \\
\hline No & 1.00 & - & & 1.00 & - & \\
\hline Yes & 1.87 & $1.77,1.98$ & $<0.01$ & 1.78 & $1.68,1.89$ & $<0.01$ \\
\hline Diagnosis of COVID-19 & & - & & & - & \\
\hline No & 1.00 & - & & 1.00 & - & \\
\hline Yes & 1.07 & $0.96,1.20$ & 0.18 & 1.06 & $0.95,1.18$ & 0.23 \\
\hline Social distancing & & - & 0.06 & & - & 0.01 \\
\hline $\begin{array}{l}\text { Adhered to social distancing for most of the } \\
\text { time, performing only visits to } \\
\text { supermarkets and pharmacies }\end{array}$ & 1.00 & - & & 1.00 & - & \\
\hline $\begin{array}{l}\text { Adhered to social distancing, but had to leave } \\
\text { to work }\end{array}$ & 1.04 & $0.97,1.12$ & 0.19 & 1.08 & $1.01,1.15$ & 0.01 \\
\hline Did not adhere to social distancing & 0.77 & $0.62,0.95$ & 0.01 & 0.86 & $0.70,1.06$ & 0.16 \\
\hline
\end{tabular}

$P R$ prevalence ratio by Poisson regression with robust adjustment of variance, $95 \%$ CI 95\% confidence interval ${ }^{a}$ Prevalence ratios for the diagnosis of general anxiety disorder in multivariable models including age, sex, race/ skin color, economic class, body mass index class, diagnosis of depression, diagnosis of COVID-19, and adherence to social distancing measures color, that is, the study of the economic dimension contemplated the ethnic-racial dimension.

Aiming at historical repair and, consequently, reducing the gap between white and non-white individuals, in 2012, the Brazilian Federal Government approved Law No. 12,711, which reserves $50 \%$ of places in undergraduate courses at federal universities (public education network) for public school students and self-declared black, brown, indigenous, and people with disabilities. This legal instrument made it possible to increase the inclusion of blacks and browns in the federal universities, from 8.7 in 2010 to $12.0 \%$ in 2018 of students who declare themselves black, and from 32.1 to $39.2 \%$ of browns [41]. Although extremely necessary to allow blacks and browns access to public universities, the proportion of black and brown university students is far from the proportions of these races/skin colors in the Brazilian population, and shows that for these groups, reaching university is a greater challenge than for young whites. It is noteworthy that just guaranteeing access is not enough, given that most of these students are in conditions of social vulnerability; student assistance policies in federal institutions of higher education have a fundamental role in maintaining these students within 
the university. The absence of student assistance policies could contribute to the increase in GAD among university students, due to the economic and social instability imposed.

In addition, our findings indicate that younger individuals seem to be at greater risk of experiencing anxiety than older individuals. During the COVID-19 pandemic, it was observed that older individuals had better emotional well-being and less reactivity to stressors, while younger individuals had more concerns related to COVID-19 [42]. Furthermore, university students who faced a lack of interaction and emotional support and physical isolation were associated with worse mental health, which may contribute to higher levels of anxiety in this population [43].

According to official data from the Ministry of Education of Brazil and the Instituto Nacional de Estudos e Pesquisas Educacionais Anísio Teixeira, most of this population is female $(57.0 \%)$; the average age of students is $25.6 \pm 7.4$ years, with $99.3 \%$ of Brazilian university students aged between 18 and 59 years. As for race/skin color, $41.8 \%$ of the students reported being white, $28.8 \%$ and $7.0 \%$, brown mixed race and black, respectively. In comparison, our sample has a similar average age and a higher percentage of women (73.5\%). In addition our sample contained a greater number of individuals who declared themselves brown (37.2\%) and black (12.7\%) [44]. Regarding the economic comparison, estimates suggest that about $1.5 \%$ of university students belong to economic class A and $22.7 \%$ to economic class E [45]. These data differ from those found in our sample, in which $13.8 \%$ belonged to economy class A and only $5.5 \%$ economic class D-E. Comparisons should be carried out extremely carefully, given that the methods for determining economic classes are different. The method used to determine the estimates of the distribution of economic classes in the population of Brazilian university students is based only on per capita household income, while the instrument we used in our research considers the ownership of assets, the level of education of the head of the family (the person who contributes most of the family income), and access to basic public services (piped water and street paving). Nevertheless, we point out that our sample was composed of more individuals from economic class A and fewer individuals from economic class D-E, which may induce over and under-representation of students from higher and lower economic classes, respectively.

The present study has some limitations. First, we emphasize that given the negationist positioning of the federal government and the different epidemiological scenarios in different regions of Brazil, measures of social distancing were applied differently between the units of the federation. This fact may have influenced the magnitude of the measures to restrict the circulation of people and, consequently, the levels of stress and anxiety in the population of different locations. Another limitation is the self-report of the race/skin colour of the participants, which may not correspond exactly to the individuals' genetic ancestry. However, data from the possible largest study conducted in Brazil on the relationship between self-declaration of race/skin color and genomic ancestry observed that African genomic ancestry is a strong predictor of self-declaration of race/skin color black and brown, as well as the proportion of black and brown inhabitants in the individuals' residential territory [46]. In addition, the small number of participants who declared themselves yellow and indigenous made it impossible to analyze with these population groups. It is worth mentioning that we did not include in our data collection information about the contamination of family members by COVID-19 and the severity of symptoms, questions about the complete suspension or adoption of the remote education system, and the delay in completing the course and obtaining the diploma due to the pandemic. Moreover, in the multivariable models, there were no interaction in terms of race/skin color with social class, adherence to social distancing measures, and obesity. Hence, possible interferences of these factors may have contributed to the higher risk of GAD for black college students than for white and brown college students. Future research should investigate these interactions for further clarification. Finally, the fear of moral judgment about whether or not to adhere to social distancing measures to contain the spread of COVID-19, may have influenced the self-report of this information in our study. However, the absence of the researcher face to face with the participant can lessen the fear of moral judgment.

As strengths of the study, we highlight that most of the literature on the subject is composed of research conducted in the USA. In this sense, the development of research in Brazilian territory is of paramount importance, as the two countries present cultural, social, economic, and historical differences that can influence the extrapolation of the American results to our population. Thus, in view of the scarcity of Brazilian studies that evaluated the relationship between race/skin color and GAD, our study has an important relevance for the advancement of knowledge of this relationship. In addition, as far as we know, this is the first study that aimed to determine whether there are racial differences in GAD in Brazilian university students during the COVID-19 pandemic. We also highlight that we reached a large sample of university students in Brazil, with distribution among all regions of the country, making it possible to capture the Brazilian social, economic, and cultural diversity in our sample.

\section{Conclusion}

In conclusion, the findings of the present study point to a possible racial difference in GAD among Brazilian university students, in which those who declared race/skin color as black showed a greater risk for GAD than those who declared race/skin color as white or brown. We highlight the existence of many gaps in 
the scientific knowledge of the determinants of GAD and its relationship with the race/skin color of individuals, thus becoming a fruitful field for scientific investigations, particularly in Brazil, which has a multiracial population and immense economic, cultural, and social diversity. Finally, we emphasize that race/ skin color and its relationship with mental health must be investigated and understood not only from a biological perspective, but also from a social perspective resulting from a nation's historical, political, and cultural experiences.

Author Contribution A.E.S.J. contributed to the conception and design of the study, data collection, statistical analysis, data interpretation, and writing of the manuscript. M.L.M., A.D.S.O., and D.R.S.P. contributed to the data collection, data interpretation, and writing of the manuscript. I.R.O.M.P. and N.B.B. contributed to the data interpretation, writing of the manuscript, and critical review of the intellectual content. All authors reviewed and approved the final version of the work.

Funding A.E.S.J. is supported by the Coordenação de Aperfeiçoamento de Pessoal de Nível Superior-Brazil (CAPES) research fellowships (grant number $88887.480702 / 2020-00)$. M.L.M. is supported by the Coordenação de Aperfeiçoamento de Pessoal de Nível Superior-Brazil (CAPES) research fellowships (grant number 23065.005919/2021-75). D.R.S.P. is supported by the Coordenação de Aperfeiçoamento de Pessoal de Nível Superior-Brazil (CAPES) research fellowships (grant number 23065.005919/2021-75). I.R.O.M.P. is supported by the Coordenação de Aperfeiçoamento de Pessoal de Nível Superior-Brazil (CAPES) research fellowships (grant number 88887.465281/2019-00).

\section{Declarations}

Ethics Approval The research protocol was approved by the Research Ethics Committee of the Universidade Federal de Alagoas (process number 4.410.403).

Conflict of Interest The authors declare no competing interest.

\section{References}

1. WHO. Coronavirus disease (COVID-19). World Health Organization. 2020. https://www.who.int/emergencies/diseases/ novel-coronavirus-2019. Accessed April 2021.

2. Burns J, Movsisyan A, Stratil JM, Coenen M, Emmert-Fees KM, Geffert K, et al. International travel-related control measures to contain the COVID-19 pandemic: a rapid review. Cochrane Database of Systematic Reviews. 2021;2021. https://doi.org/10. 1002/14651858.CD013717.pub2.

3. Lewnard JA, Lo NC. Scientific and ethical basis for socialdistancing interventions against COVID-19. Lancet Infect Dis. 2020;20(6):631-3. https://doi.org/10.1016/S1473-3099(20)301900.

4. Cao W, Fang Z, Hou G, Han M, Xu X, Dong J, et al. The psychological impact of the COVID-19 epidemic on college students in China. Psychiatry Res. 2020;287:112934. https://doi.org/10.1016/j. psychres.2020.112934.

5. Ellis WE, Dumas TM, Forbes LM. Physically isolated but socially connected: psychological adjustment and stress among adolescents during the initial COVID-19 crisis. Canadian Journal of Behavioural Science/Revue canadienne des sciences du comportement. 2020;52(3):177-87. https://doi.org/10.1037/ cbs0000215.

6. Fernández RS, Crivelli L, Guimet NM, Allegri RF, Pedreira ME. Psychological distress associated with COVID-19 quarantine: latent profile analysis, outcome prediction and mediation analysis. $\mathrm{J}$ Affect Disord. 2020;277:75-84. https://doi.org/10.1016/j.jad.2020. 07.133.

7. Salari N, Hosseinian-Far A, Jalali R, Vaisi-Raygani A, Rasoulpoor $\mathrm{S}$, Mohammadi M, et al. Prevalence of stress, anxiety, depression among the general population during the COVID-19 pandemic: a systematic review and meta-analysis. Global Health. 2020;16(1). https://doi.org/10.1186/s12992-020-00589-w

8. Bruffaerts R, Mortier P, Kiekens G, Auerbach RP, Cuijpers P, Demyttenaere K, et al. Mental health problems in college freshmen: prevalence and academic functioning. J Affect Disord. 2018;225: 97-103. https://doi.org/10.1016/j.jad.2017.07.044.

9. Son C, Hegde S, Smith A, Wang X, Sasangohar F. Effects of COVID-19 on college students' mental health in the United States: interview survey study. J Med Internet Res. 2020;22(9). https://doi.org/10.2196/21279

10. Sankhi S, Marasine NR. Impact of COVID-19 pandemic on mental health of the general population, students, and health care workers: a review. 2020; https://doi.org/10.46405/ejms.v2i2.131

11. Heringer R. Desigualdades raciais no Brasil: síntese de indicadores e desafios no campo das políticas públicas. Cad Saúde Pública. $2002 ; 18$ (supp1). https://doi.org/10.1590/S0102311X2002000700007

12. Lopes F. Para além da barreira dos números: desigualdades raciais e saúde. Cad Saúde Pública. 2005;21(5):1595-60. https://doi.org/10. 1590/S0102-311X2005000500034.

13. Solar O, Irwin AA. Conceptual framework for action on the social determinants of health. In: Social determinants of health discussion paper 2 (policy and practice). World Health Organization. 2010. https://apps.who.int/iris/handle/10665/44489. Accessed April 2021.

14. Warner DF, Brown TH. Understanding how race/ethnicity and gender define age-trajectories of disability: an intersectionality approach. Soc Sci Med. 2011;72(8):1236-48. https://doi.org/10. 1016/j.socscimed.2011.02.034.

15. Turner RJ, Avison WR. Status variations in stress exposure: implications for the interpretation of research on race, socioeconomic status, and gender. J Health Soc Behav. 2003;44(4):488-505. https://doi.org/10.2307/1519795.

16. Williams DR, Yu Y, Jackson JS, Anderson NB. Racial differences in physical and mental health. J Health Psychol. 1997;2(3):335-51. https://doi.org/10.1177/135910539700200305.

17. IBGE - Instituto Brasileiro de Geografia e Estatística. In: Censo Demográfico 2010: Resultados gerais da amostra. IBGE; 2012. https://censo2010.ibge.gov.br/resultados.html. Accessed April 2021.

18. Brasil. Ministério da Saúde. In: Painel de casos de doença pelo coronavírus 2019 (COVID-19) no Brasil. 2021. https://covid. saude.gov.br. Accessed April 2021.

19. Associação Brasileira de Empresas de Pesquisas. Critérios de classificação econômica Brasil. São Paulo: ABEP; 2020.

20. Eveleth PB. Physical status: the use and interpretation of anthropometry. Report of a WHO Expert Committee. Am J Hum Biol. 1996;8(6):786-7. https://doi.org/10.1002/(SICI)1520-6300(1996) 8:6<786::AID-AJHB11>3.0.CO;2-I.

21. Spitzer RL, Kroenke K, Williams JBW, Löwe B. A brief measure for assessing generalized anxiety disorder. Arch Intern Med. 2006;166(10):1092-7. https://doi.org/10.1001/archinte.166.10. 1092.

22. Kroenke K, Spitzer RL, Williams JB, et al. Anxiety disorders in primary care: prevalence, impairment, comorbidity, and detection. 
Ann Intern Med. 2007;146:317-25. https://doi.org/10.7326/00034819-146-5-200703060-00004.

23. Sousa TV, Viveiros V, Chai MV, Vicente FL, Jesus G, Carnot MJ, et al. Reliability and validity of the Portuguese version of the Generalized Anxiety Disorder (GAD-7) scale. Health Qual Life Outcomes. 2015;13(1). https://doi.org/10.1186/s12955-015-02442.

24. Xiong J, Lipsitz O, Nasri F, Lui LM, Gill H, Phan L, et al. Impact of COVID-19 pandemic on mental health in the general population: a systematic review. J Affect Disord. 2020;277:55-64. https://doi. org/10.1016/j.jad.2020.08.001.

25. Kantor BN, Kantor J. Mental health outcomes and associations during the COVID-19 pandemic: a cross-sectional populationbased study in the United States. Front Psychiatry. 2020;11. https://doi.org/10.3389/fpsyt.2020.569083.

26. Merikangas KR, He JP, Burstein M, Swanson SA, Avenevoli S, Cui L, et al. Lifetime prevalence of mental disorders in U.S. adolescents: results from the National Comorbidity Survey Replication-Adolescent Supplement (NCS-A). J Am Acad Child Adolesc Psychiatry. 2010;49(10):980-9. https://doi.org/10.1016/j. jaac.2010.05.017.

27. Asnaani A, Richey JA, Dimaite R, Hinton DE, Hofmann SG. A cross-ethnic comparison of lifetime prevalence rates of anxiety disorders. J Nerv Ment Dis. 2010;198(8):551-5. https://doi.org/10. 1097/NMD.0b013e3181ea169f

28. Williams DR, González HM, Neighbors H, Nesse R, Abelson JM, Sweetman J, et al. Prevalence and distribution of major depressive disorder in African Americans, Caribbean Blacks, and NonHispanic Whites. Arch Gen Psychiatry. 2007;64(3):305-15. https://doi.org/10.1001/archpsyc.64.3.305.

29. Bastos JL, Barros AJD, Celeste RK, Paradies Y, Faerstein E. Age, class and race discrimination: their interactions and associations with mental health among Brazilian university students. Cad Saúde Pública. 2014;30(1):175-86. https://doi.org/10.1590/0102$311 \mathrm{X} 00163812$.

30. Ruschi GEC, Sun SY, Mattar R, Chambô Filho A, Zandonade E, Lima VJ. Aspectos epidemiológicos da depressão pós-parto em amostra brasileira. Rev Psiquiatr Rio Gd Sul. 2007;29:274-80. https://doi.org/10.1590/s0101-81082007000300006.

31. Fry PH. A persistência da raça: ensaios antropológicos sobre o Brasil e a África Austral. Rio de Janeiro: Civilização Brasileira; 2005.

32. Hasenbalg C. Discriminação e desigualdades raciais no Brasil. $2^{\mathrm{a}}$ ed. Belo Horizonte: Editora UFMG; 2005.

33. Daflon VT, Carvalhaes F, Feres JJ. Deeper than skin: Browns' and Blacks' perceptions of discrimination in Brazil. Dados Rev. Ciênc. Sociais. 2017;60(2):293-330. https://doi.org/10.1590/ 001152582017121.

34. Pascoe EA, Richman LS. Perceived discrimination and health: a meta-analytic review. Psychol Bull. 2009;135:531-54. https://doi. org/10.1037/a0016059.
35. Williams DR, Mohammed SA. Discrimination and racial disparities in health: evidence and needed research. J Behav Med. 2008;32: 20-47. https://doi.org/10.1007/s10865-008-9185-0.

36. Shim RS, Ye J, Baltrus P, Fry-Johnson Y, Daniels E, Rust G. Racial/ethnic disparities, social support, and depression: examining a social determinant of mental health. Ethn Dis. 2012;22(1):15-20.

37. Williams MT, Chapman LK, Wong J, Turkheimer E. The role of ethnic identity in symptoms of anxiety and depression in African Americans. Psychiatry Res. 2012;199(1):31-6. https://doi.org/10. 1016/j.psychres.2012.03.049

38. Macinko J, Mullachery P, Proietti FA, Lima-Costa MF. Who experiences discrimination in Brazil? Evidence from a large metropolitan region. Int J Equity Health. 2012;11(1):80. https://doi.org/ 10.1186/1475-9276-11-80.

39. Smolen JR, Araújo EMD. Raça/cor da pele e transtornos mentais no Brasil: uma revisão sistemática. Ciênc Saúde Coletiva. 2017;22: 4021-30. https://doi.org/10.1590/1413-812320172212.19782016.

40. Chor D, Lima CRDA. Aspectos epidemiológicos das desigualdades raciais em saúde no Brasil. Cad Saúde Pública. 2005;21:1586-94. https://doi.org/10.1590/s0102-311x2005000500033.

41. Associação Nacional dos Dirigentes das Instituições de Ensino Superior - ANDIFES. V Pesquisa nacional de perfil socioeconômico e cultural dos graduandos das IFES -2018. ANDIFES. 2019. https://www.andifes.org.br/wp-content/uploads/ 2019/05/V-Pesquisa-Nacional-de-Perfil-Socioeconomico-eCultural-dos-as-Graduandos-as-das-IFES-2018.pdf Accessed 22 Jun 2021.

42. Klaiber P, Wen JH, DeLongis A, Sin NL. The ups and downs of daily life during COVID-19: age differences in affect, stress, and positive events. J Gerontol B Psychol Sci Soc Sci. 2021;76(2):e30 7. https://doi.org/10.1093/geronb/gbaa096.

43. Elmer T, Mepham K, Stadtfeld C. Students under lockdown: comparisons of students' social networks and mental health before and during the COVID-19 crisis in Switzerland. PLoS One. 2020;15(7): e0236337. https://doi.org/10.1371/journal.pone.0236337.

44. INPE. Sinopse Estatística da Educação Superior 2018. INPE: Brasília; 2019.

45. Instituto SEMESP. Mapa do ensino superior no Brasil - 2020. Instituto SEMESP. 2020. https://www.semesp.org.br/wp-content/ uploads/2020/04/Mapa-do-Ensino-Superior-2020-InstitutoSemesp.pdf Accessed 22 Jun 2021.

46. Chor D, Pereira A, Pacheco AG, Santos RV, Fonseca MJM, Schmidt MI, et al. Context-dependence of race self-classification: results from a highly mixed and unequal middle-income country. PloS One. 2019;14(5). https://doi.org/10.1371/journal.pone. 0216653.

Publisher's Note Springer Nature remains neutral with regard to jurisdictional claims in published maps and institutional affiliations. 